\title{
Drop Weight Impact Behaviour of Quasi-Isotropic CFRP Composite Embedded with Mwcnts Synthesized by Arc Discharge Method
}

\author{
Nand Kishore Singh ${ }^{1 *}$, KK Singh ${ }^{2}$, Prashant Rawat ${ }^{3}$ and Atul Sharma ${ }^{4}$ \\ ${ }^{1}$ Department of Mechanical Engineering, Dayananda Sagar University, India \\ ${ }^{2}$ Department of Mechanical Engineering, Indian Institute of Technology (ISM), India \\ ${ }^{3}$ School of Mechanical Engineering, Ligaya's University, India \\ ${ }^{4}$ Department of Mechanical Engineering, Adamas University, India
}

*Corresponding author: Nand Kishore Singh, Department of Mechanical Engineering, Dayananda Sagar University, India, Email: incredablespace@gmail.com

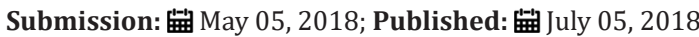

\begin{abstract}
The drop weight low-velocity impact (LVI) response of quasi-isotropic symmetric carbon/epoxy composite reinforced with multiwall carbon nanotubes (MWCNTs) is investigated. The MWCNTs were synthesized by using arc discharge method. The carbon nanotubes were mixed at three different percentages in the epoxy resins as a secondary reinforcement. The drop weight impact test was performed according to ASTM D7136 standard at $6 \mathrm{~m} / \mathrm{sec}$ indent velocity (impact energy=94.14J) and it has been concluded that doping of nanotubes as secondary reinforced in woven polymer composites influences the low velocity impact resistant.However, mixing of these nanotubes above a certain wt\% reduces the laminate performance (at $5 \mathrm{wt} \%$ ) due to the improper wetting and agglomeration of carbon nanotubes. The outcome of the experimental work justified that the improvement in energy absorption, damage tolerance under drop weight impact test is significant by mixing in-house produced multiwall carbon nanotubes.
\end{abstract}

Keywords:MWCNTs synthesis; CFRP; LVI; Energy absorption; Damage

\section{Introduction}

Carbon nanotubes [1] are well-known nanomaterials with exceptional mechanical, electrical and thermal properties. These nanoparticles may be incorporated with polymer composites as a primary and/or secondary reinforcement [2-4]. This reinforcement overcomes several limitations related to conventional polymer composites and enhances material performance under loading [4]. Impact damage tolerance of fiber reinforced polymer composites is a serious concern and a real life problem in several sectors such as, aerospace, automobile and marine industries [5]. The low-velocity impact causes matrix cracking, delamination and fiber fracture. When carbon nanotubes are used as reinforcement, they provide strong interfacial adhesion between matrix and nanoparticle. Therefore, enhancement in overall mechanical properties is achieved [6].

On the basis of coaxial tubes carbon nanotubes can be dived into two categories
A. Single-wall carbon nanotubes (SWCNTs)
B. Multiwall carbon nanotubes (MWCNTs).

SWCNTs doping is 'the pull-out effect' from the bundles (ropes) whereas MWCNTs offers advantages over this limitation as well as provide better load transfer in polymer composites [6]. Rawat et al. [7] worked on analysis of impact damage tolerance of FRPs using MWCNTs as reinforcement at various doping percentages. Commonly the synthesis process of multiwall carbon nanotubes adopted is chemical vapor deposition (CVD). The limitation of the method is limited quantity production of multiwall carbon nanotubes. Moreover, MWCNTs produced with the arc discharge process does not require any expensive machinery and/or special arrangements. Furthermore, the arc discharge process is a mass production and cost effective technique for MWCNTs synthesis [8].

To investigate the mechanical properties of two and/or three phase polymer composites mixed with multiwall carbon nanotubes several types of research have been conducted [9-11]. Various methods have been developed and proposed to improve the damage tolerance of FRPs such as hybrid layup [12,13], sandwich composites [14], nano to microparticles/fiber reinforced composites [15] and designed laminates [16,17].

During LVI in fiber/epoxy composites, the dominant damage mechanisms are: matrix cracking (crack generation), delaminating (interface failure) and fiber fracture [18]. Matrix modification using MWCNTs provides better load transfer [19] and improved 
interfacial characteristics [20] therefore improved damage tolerance is attained. Kostopoulos et al. [4] studied the impact and after impact properties by adding multiwall carbon nanotubes in CFRP laminates. The results of this experimental investigation justified the improvement in energy absorption and the cause of improvement in energy absorption was larger surface area due to MWCNTs. Additionally, matrix toughing effect in modified matrix stops crack propagation resulting less delaminating for multiwall nanotubes mixed CFRPs. Soliman et al. [21] performed drop weight impact testing of COOH-MWCNT/CFRP woven fabric laminates at three doping percentage i.e. $0.5,1$ and $1.5 \%$ of resins. A $50 \%$ improvement in penetration energy was analyzed at 1 and $1.5 \%$ reinforcement of $\mathrm{COOH}-\mathrm{MWCNTs}$. It is also reported that rate of energy absorption increases with the increase in energy applied over laminates. The reduction in visible damage area i.e. $75 \%$ reduction in pyramid height and $20 \%$ reduction in damage width was reported at $1.5 \mathrm{wt} . \%$ of $\mathrm{COOH}-\mathrm{MWCNT}$ reinforcement. Tehrani et al. [10] analyzed the impact damage assessment of MWCNT doped woven carbon fiber composites at $2 \mathrm{wt} \%$ of the total matrix system. Mixing of MWCNTs above $2 \mathrm{wt} \%$ in matrix causes improper wetting of fibers and thus the performance of the composite laminate reduced above this doping value. Results of this study reported for higher energy absorption capacity of MWCNTs modified laminates under high strain or punch tests, reduction in damage area was analyzed as multiwall carbon nanotubes provide a stiff barrier for

Specimen Preparation

\section{MWCNT synthesis}

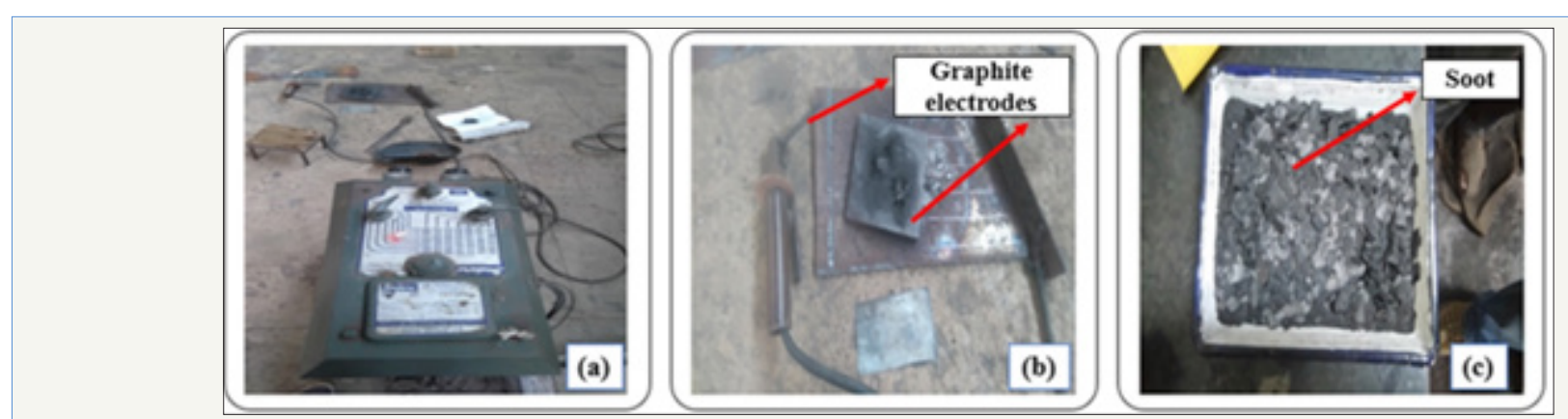

Figure 1: (a) Arc-discharge welding set-up, (b) Plate and rod electrodes, (c) Prepared soot.

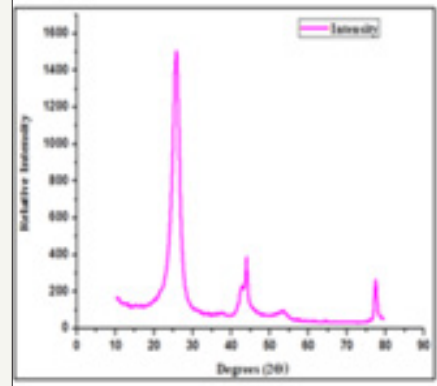

(a)

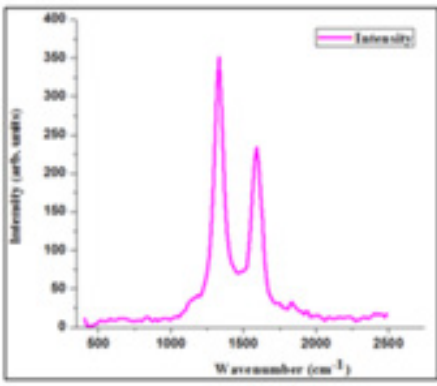

(b)

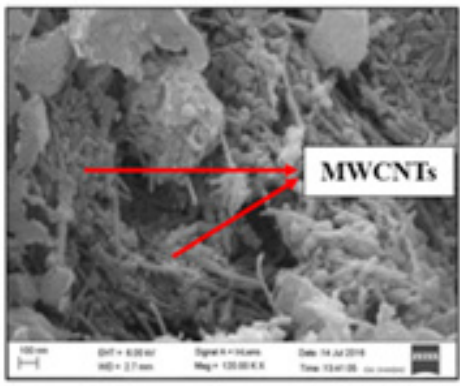

(c)

Figure 2: Properties of the MWCNTs (a) X-Ray diffraction pattern, (b) Raman spectrum pattern, (c) FESEM image of surface modified MWCNTs.

The multi-wall carbon nanotubes were produced by using arcdischarge technique [23] which is a large scale synthesis method
[24]. The MWCNTs were produced using Indarc-300ST (manual arc welding AC arc-discharge set-up) in-house facility with 25-300 Amp 
current and 80-100 Volts capacity. For MWCNT synthesis arc was generated at $300 \mathrm{Amp}$ and $80 \mathrm{~V}$. All experiments were carried out in the open-air atmosphere with $99.0 \%$ pure graphite electrodes (rods and rectangular plate). The rod was $300 \mathrm{~mm}$ in length with $10 \mathrm{~mm}$ diameter while rectangular electrode plate (Figure 1) was $15 \mathrm{mmX} 10 \mathrm{mmX} 2 \mathrm{~mm}$. The gap between rod and plate was $1-2 \mathrm{~mm}$ manually and the arc was made by moving graphite rod over the plate. Using the same process soot was deposited on a rectangular electrode plate and collected after arcing process. This soot was powdered by using a ball mill. This fine powder carries impurities like fullerenes, amorphous carbon and other nano carbon particles. Therefore purification of synthesized MWCNTs was done in steps. Figure 2 represents the properties of the multiwall carbon nanotubes prepared using the arc-discharge method.

\section{Purification of MWCNT powder}

A. Washing of MWCNT powder by distilled water at an elevated temperature of $40{ }^{\circ} \mathrm{C}$ for removing dust particles.

B. Heating of fine powder at $600 \pm 20^{\circ} \mathrm{C}$ inside a closed muffle furnace for removing amorphous carbon particles.

C. Treatment (for 4-5hrs.) with toluene for removing fullerenes present in the MWCNT power.

D. Liquid phase oxidation of MWCNT powder using 20\% $\mathrm{H}_{2} \mathrm{O}_{2}$ (hydrogen peroxide) for $2 \mathrm{hrs}$. This process removed maximum amorphous carbon impurities and also modified MWCNTs surface properties [25].

\section{Stacking Sequence of Laminates:}

Plain woven carbon fabric having weft and wrap in $0^{\circ}$ and $90^{\circ}$ direction $(0,90)$ and plain bi-directional woven carbon fabric having weft and wrap in $+45^{\circ}$ and $-45^{\circ}$ direction- $(+45,-45)$ were used for fabrication of quasi-isotropic symmetric carbon-woven/ epoxy laminates. Stacking sequence used for symmetric CFRP laminates was $[(0,90) /(+45,-45) /(+45,-45) /(0,90)]$.

Stiffness matrixes of laminates are [16]:

1. Bending-extension coupling matrix,

$[B]=0$............(i)
2. Extension stiffness matrix $[\mathrm{A}]$

$A_{i j}=4 t\left\{\left(\overline{Q_{i j}}\right)_{(0,90)}+\left(\overline{Q_{i j}}\right)_{(+45,-45)}\right\}$

3. Bending stiffness matrix $[D]$

$D_{i j}=\frac{64}{3} t^{3}\left\{\left(Q_{i j}\right)_{(0,90)}+\left(Q_{i j}\right)_{(+45,-45)}\right\}$

Here,

$\mathrm{A}_{\mathrm{ij}}$ and $\mathrm{D}_{\mathrm{ij}}$ represent components of extension stiffness matrix and bending stiffness matrix respectively,

$\mathrm{t}$ is the thickness of each layer, $\overline{Q_{i j}}$ is transferred reduced stiffness matrix of the layer.

Using above mentioned stacking sequence, four types of CFRP laminates doped at 1,2,3, and 5 were fabricated. However, the objective of the study focuses on

A. The symmetric laminate of plain woven carbon fabric/ epoxy without MWCNTs as a reference.

B. The symmetric laminate of plain woven carbon fabric/ epoxy doped at $2 w t \%$ of MWCNTs (energy absorption is optimum).

C. The symmetric laminate of plain woven carbon fabric/ epoxy with $5 w t \%$ MWCNTs (energy absorption is lowest).

\section{Fabrication of laminates (doped with MWCNTs) having stacking mentioned above sequence}

The multiwall carbon nanotubes were dried in a closed air oven for $5 \mathrm{hrs}$ for removing any moisture content. Initially, to remove agglomerations, MWCNTs (as per calculated wt\%) were mixed in ethanol and sonicated for 30 minutes using probe ultrasonicator (OSCAR ULTRASONICS). Now, Bisphenol-A based epoxy (purchased from Atul ltd., Gujarat, India) was added to ethanol/MWCNTs solution. Additionally, the solution was sonicated for $1 \mathrm{hrs}$ at $60^{\circ} \mathrm{C}$. To prevent MWCNTs from surface damage continuous sonication was avoided [26]. The prepared solution was kept in a vacuum oven for 4 days to remove ethanol and air bubbles formed in the solution. After removing the MWCNT/epoxy solution the K-6 hardener (Atul Itd., Gujarat, India) was mixed in 10:1 (epoxy: hardener) ratio and again sonicated for 10 minutes.

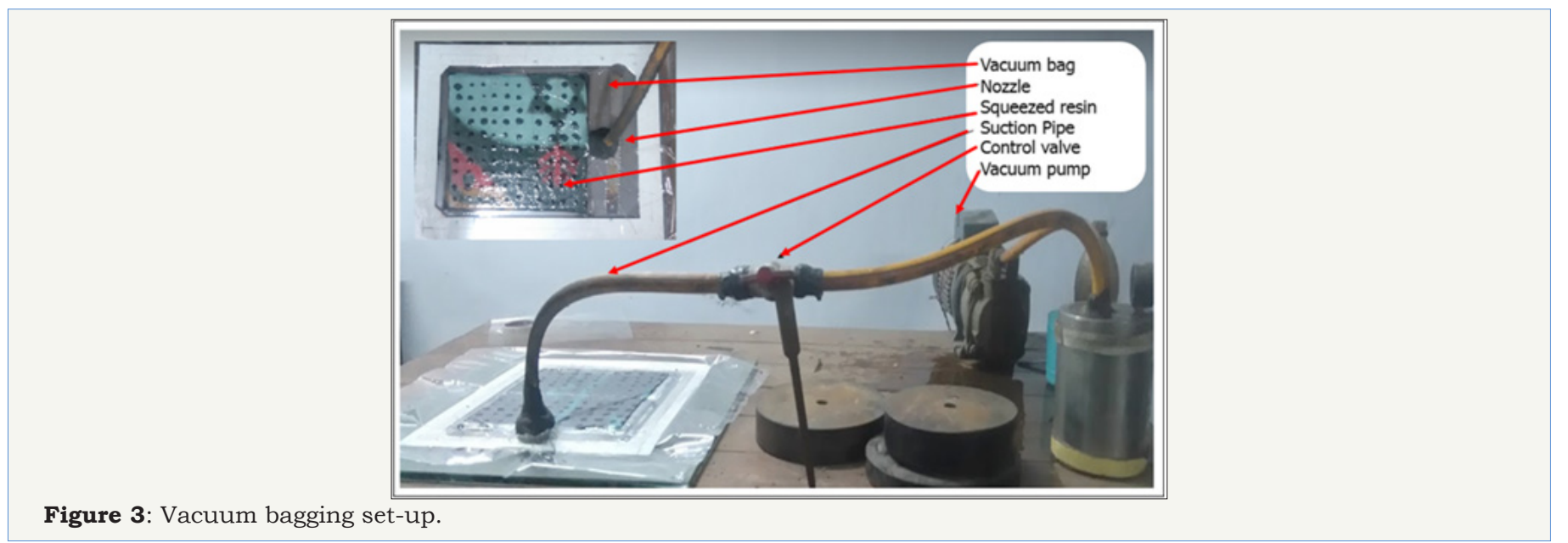


Three phase CFRP laminate was prepared by hand lay-up technique assisted by vacuum bagging method. The first woven layer $(0,90)$ was placed on a flat glass surface and prepared resin solution was applied using a soft brush followed by a second layer $(+45,-45)$. An iron roller was rolled to expel extra resins form the eight-layered symmetrical design wet laminate $[(90,0) /(-45,+45) /$

\section{Experimental Setups and Testing}

$(-45,+45) /(90,0)]$. This wet laminate was placed inside vacuum bag (Figure 3) and using vacuum pump pressure of $700 \mathrm{~mm}$ of $\mathrm{Hg}$ was attained. This vacuum pressure was applied for 30 minutes and then released. Load of $30 \mathrm{Kg}$. was applied over wet laminate and it was cured for next $24 \mathrm{hrs}$ in room atmospheric conditions.

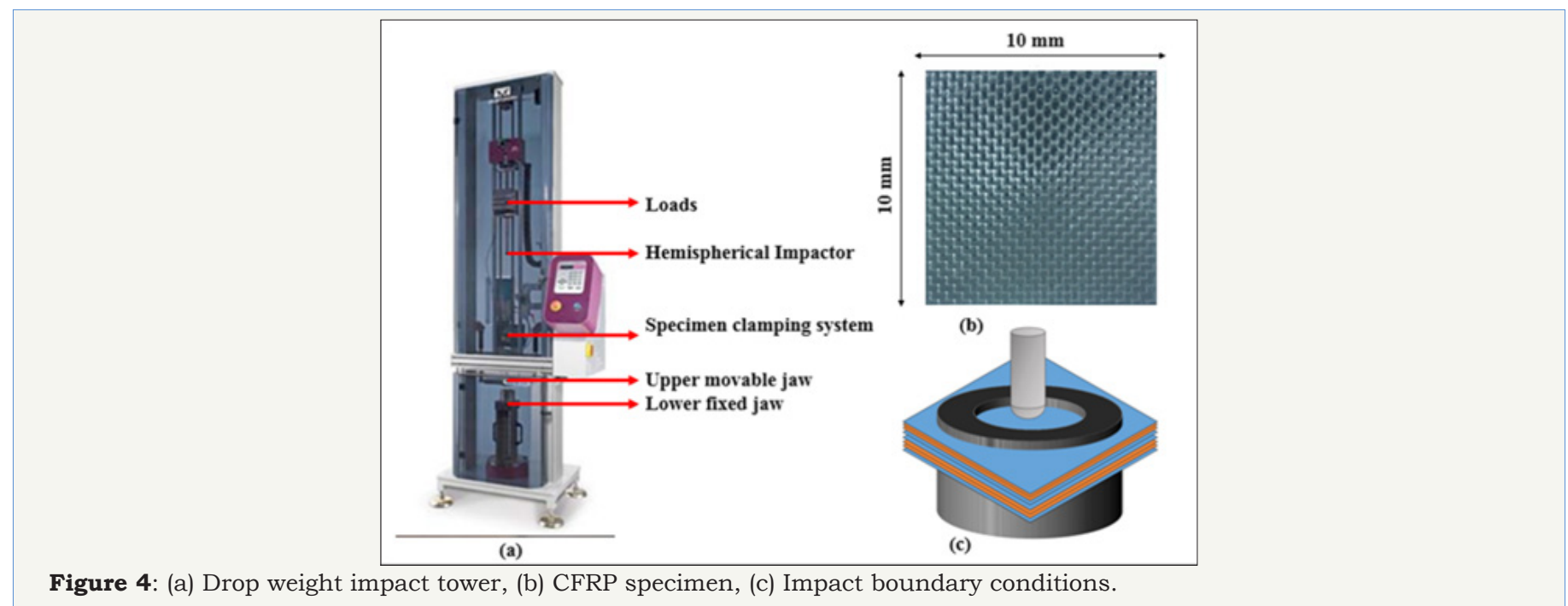

ASTM D7136 was followed in conducting drop weight test of specimens on Instron-CEAST 9350 machine. Six samples of symmetric CFRP laminates having $0 \mathrm{wt} \%, 2 \mathrm{wt} \%$ and $5 \mathrm{wt} \%$ MWCNTs are impacted by hemispherical headed cylindrical impactor having an impact energy of $94.14 \mathrm{~J}$ corresponding to $6 \mathrm{~m} /$ sec. A square specimen having a dimension of $100 \mathrm{~mm}$ and depth of $3.9 \pm 0.1 \mathrm{~mm}$ was clamped rigidly in frame leaving the central circular unsupported area of $314 \mathrm{~mm}^{2}$ for impact as shown in Figure 4. In all fabricated laminates, fiber failure occurred at impact energy of 94.14J. Hence, impact analysis of plain woven carbon fabric/epoxy laminates with and without MWCNTs was conducted at impact energy of 94.14J.

\section{Result and Discussion}

\section{Characterization of synthesized MWCNTs}

The synthesized multiwall carbon nanotubes were characterized by using X-ray diffraction, Raman spectroscopy and FESEM scanning (Figure $2 \& 3$ ).

A. From XRD, the peak observed for synthesized MWCNTs was between 20 to 30 degrees.

B. Raman spectroscopy shows presence of MWCNTs in D and G-band.

C. In FESEM images, small needle like structure can be observed.

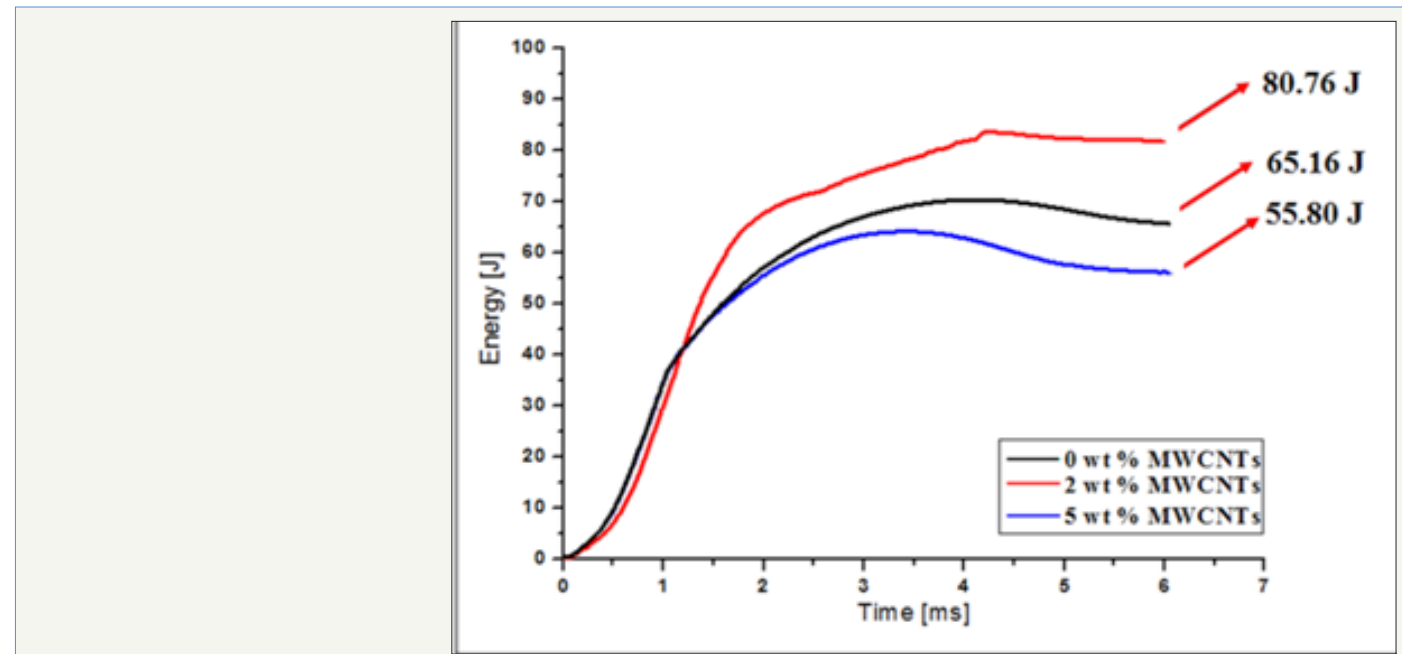

Figure 5: Energy-Time plots for symmetric CFRP laminate at 94.14J. 
From the above characterizations, it can be concluded that the synthesized nano-powder contained multiwall carbon nanotubes having diameter of $15-50 \mathrm{~nm}$, and length of 200-500 nm. On impacting at an energy of 94.14J fiber fails in all three types of laminates showing similar nature of energy-time graph. Energy absorbed by a symmetric laminate of a plain woven carbon fiber/ epoxy without MWCNTs is 65.16J, which increased to 80.76J on the addition of $2 \mathrm{wt} \%$ MWCNTs as shown in Figure 5. On contrary to this addition of $5 \mathrm{wt} \%$ MWCNTs reduces the energy absorption to $55.80 \mathrm{~J}$ which is a reduction of $14.36 \%$. As shown in Figure 6, the increased viscocity of the epoxy resins is responsible for the inappropriate impregnation of the carbon fibers. Inappropriate wetting leads to weak interfacial bond between fiber and matrix. This improper wetting leads to poor interface bonding, and cracks initiation and propagation in laminates. Absorbed energy of the laminate shows an increase of $23.94 \%$ on mixing $2 \mathrm{wt} \%$ of MWCNTs over neat CFRP. This increase is observed because the mixture of epoxy and $2 w t \%$ MWCNTs wets/impregnates fibers as good as in case of laminate without MWCNTs (Figure 6), and MWCNTs in matrix acts as a crack arrester by bridging between crack surfaces in the impacted area.
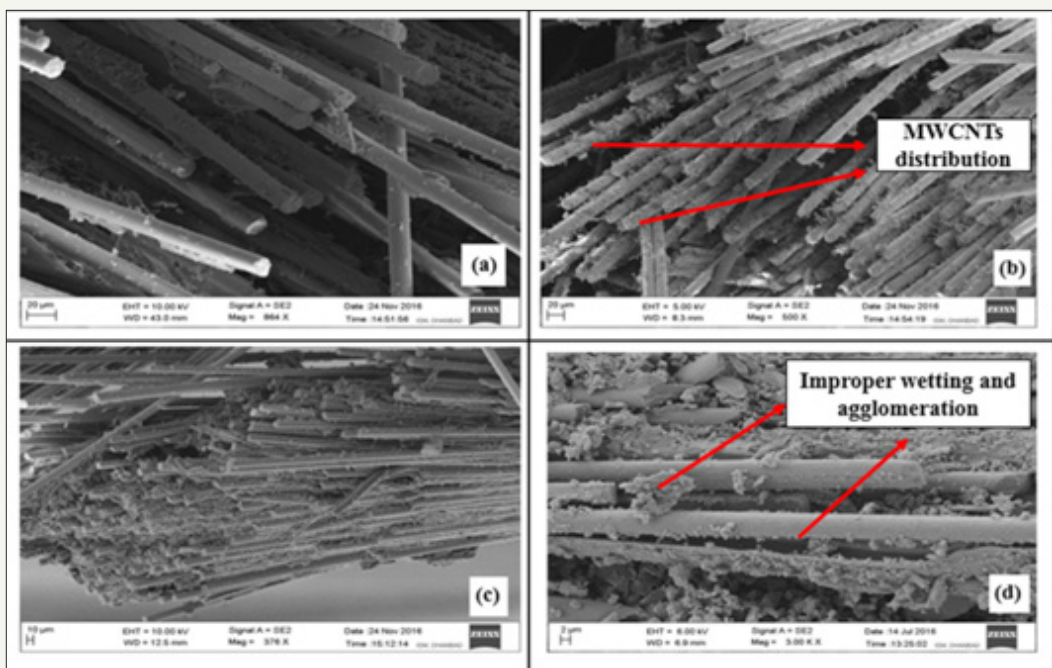

Figure 6: FESEM image of interface of fiber and epoxy mixed with (a) 0wt\%; (b) 2wt\%; (c) 5wt\% MWCNTs; (d) Agglomeration of MWCNTs at 5wt\% MWCNTs reinforcement

\section{Force-time relation}

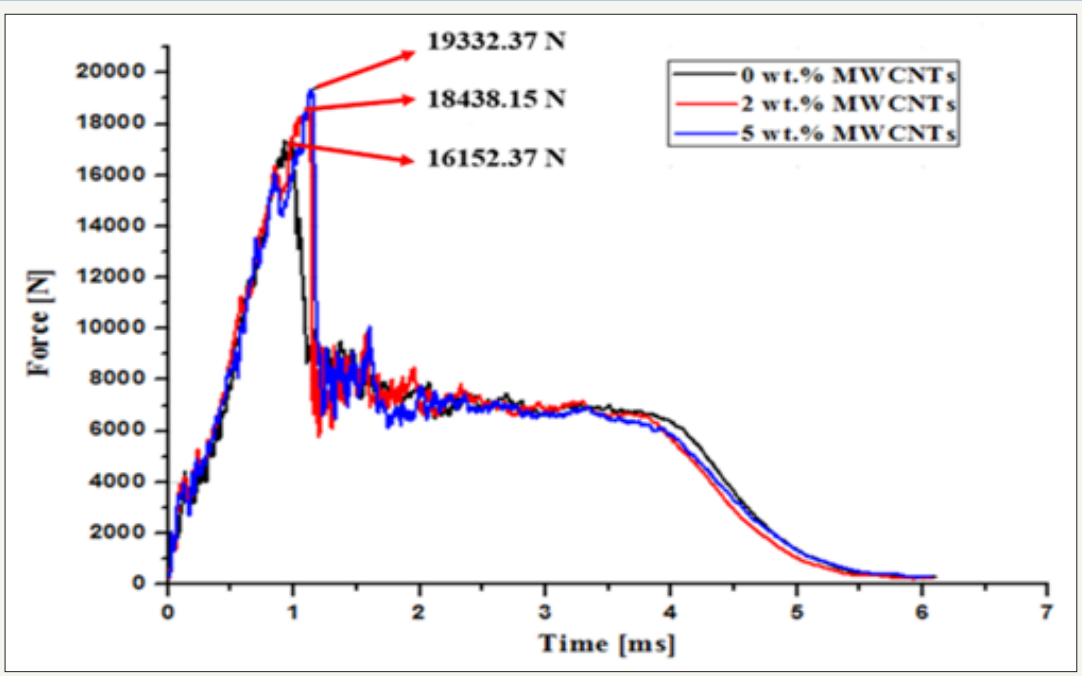

Figure 7: Force-Time plots for symmetric CFRP laminate at 94.14J.

Figure 7 shows similar nature of force-time graph for all three (epoxy with $0 w t \%, 2 w t \%$ and $5 w t \%$ MWCNTs) types of laminates. In the beginning, force increases slowly which is the result of oscillation of the laminate after the first contact of the impactor. When, the laminate returns back upword, the force increases steeply to its maximum value. After reaching the maximum value, there is a sudden drop in force signifying initiation of fiber breakage. Then several small peaks and valleys signify redistribution (reloading and unloading) of loads after breakage of each fiber. Maximum load carrying capacity of laminate with neat epoxy (0wt\% MWCNTs) is $16.15 \mathrm{KN}$. On mixing $2 \mathrm{wt} \%$ MWCNTs and $5 \mathrm{wt} \%$ MWCNTs laminate show a slight increase of $2.29 \mathrm{KN}$ and $3.18 \mathrm{KN}$ respectively. 
Upgradation of epoxy by MWCNTs does not bring significant improvement in load carrying capacity, which is accredited to the fact that fibers govern the load carrying capability of the composites. Even the increasing weight percentage of MWCNTs in epoxy leads to a viscous solution which does not impregnate fabric and also leads to the formation of MWCNTs agglomerates. Improper wetting of fabric and MWCNTs agglomerates leads to weak interface between matrix and fiber, and matrix and MWCNTs respectively. These week interfacial bonds fail in effective transfer of load from fiber to matrix and matrix to MWCNTs. Hence, load carrying capacity shows a slight improvement on MWCNTs addition.

The typical failure pattern of all composite plates can be divided in two categories visible damage and internal layer failure or delaminating. The pyramidal fracture is attributed to the plain woven carbon fabric used in the composite. The laminate fracture involves fiber and matrix fracture, which is quantified by height and width of pyramid formed by damage. The height (h) of damage is $8 \mathrm{~mm}, 4.8 \mathrm{~mm}$ and $11 \mathrm{~mm}$ due to the addition of $0 \mathrm{wt} \%$, $2 \mathrm{wt} \%$ and $5 \mathrm{wt} \%$ MWCNTs respectively. Similarly, the width (w) of damage due to the addition of $0 w t \%, 2 w t \%$ and $5 w t \%$ MWCNTs is $23.6 \mathrm{~mm}, 18 \mathrm{~mm}$ and $27.54 \mathrm{~mm}$ respectively. As shown in Figure 8 \& 9 , the size of the damage on addition of $2 \mathrm{wt} \%$ multiwall carbon nanotube is small in comparison with undoped CFRP composite. This is attributed to interaction between MWCNTs and matrix that arrests the development of damage by bridging around the crack in impacted area. On an antagonistic laminate damage increases on embedding 5wt\% MWCNTs which is even larger than the damage of laminate with pure epoxy. Doping of $5 w t \%$ MWCNTs forms viscous solution of epoxy and leads to formation of agglomeration (Figure 6). This viscous solution and MWCNTs agglomerates leads to weak fiber-matrix and MWCNTs-matrix boundary respectively, which reduces connecting action leading to larger damage region in comparison to laminate with neat (0wt\% MWCNTs) epoxy.

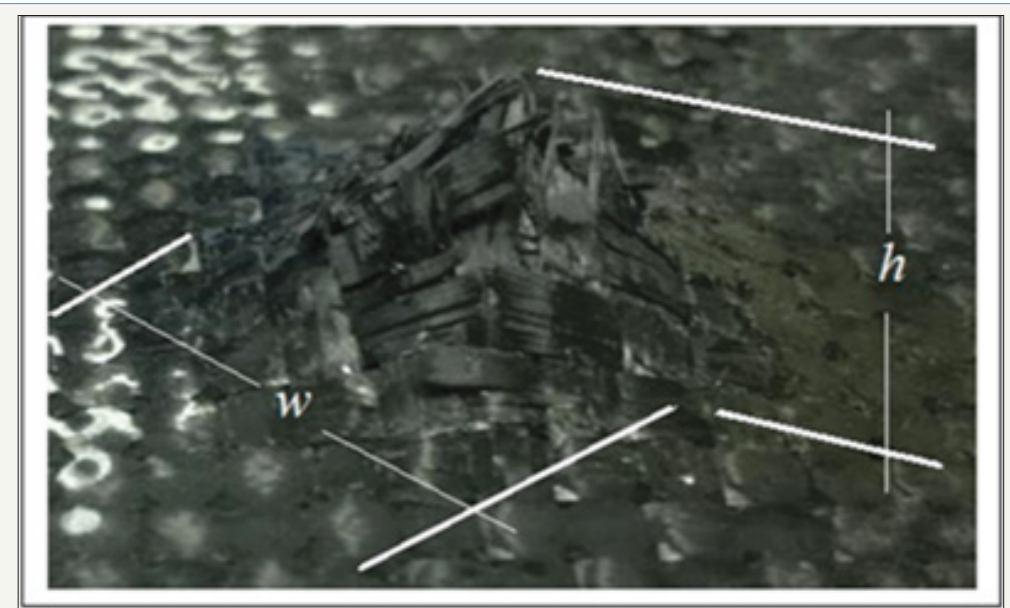

Figure 8: Calculation of visible/pyramidal damage.
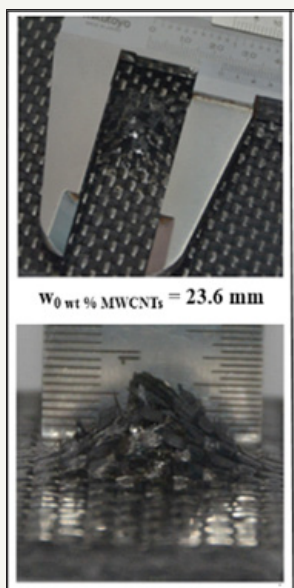

$\mathrm{h}_{0 \mathrm{mt}}$.6 $\mathrm{VNTCVTs}_{\mathrm{s}}=8.0 \mathrm{~mm}$

(a)

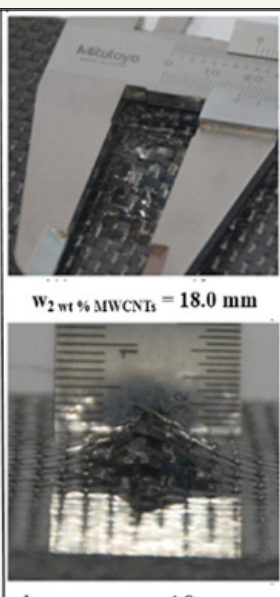

(b)

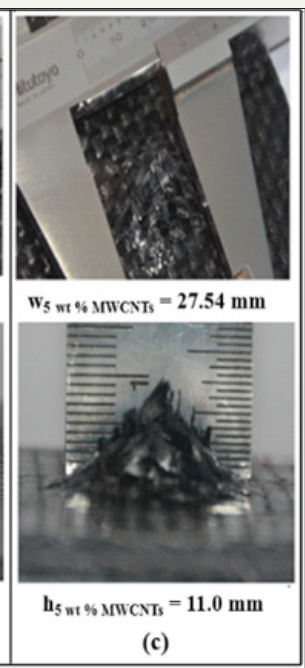

Figure 9: Pyramidal damage for (a) Neat CFRP; (b) 2.0 wt.\% MWCNT doping; (c) 5.0 wt.\% MWCNT doping.

Internal damage inside laminate (Figure 10) is calculated using KSI scanning acoustic v- 400 series microscope. Scanning of damage CFRP laminate was done over $45 \mathrm{mmX} 45 \mathrm{~mm}$ rectangular area. The overall internal damage was calculated and shown in Figure 10 where the maximum damage area of $1326.29 \mathrm{~mm}^{2}$ was observed in laminate doped with $5 \mathrm{wt} \%$ of MWCNTs which is attributed to the improper wetting and agglomeration of nanoparticles in resins as discussed by FESEM analysis. The damage area in $5 \mathrm{wt} \%$ reinforced 
sample was $32.20 \%$ more than the unmodified CFRP composites. Furthermore, the minimum damage area was observed for $2 \mathrm{wt} \%$ shows better interfacial characteristics of MWCNT reinforced resins. At $2 \mathrm{wt} \%$ mixing of nanotubes reduced $30.17 \%$ as compare to CFRP laminate with neat epoxy.

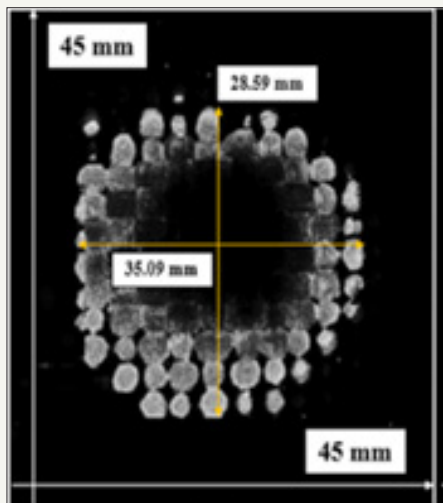

(a)

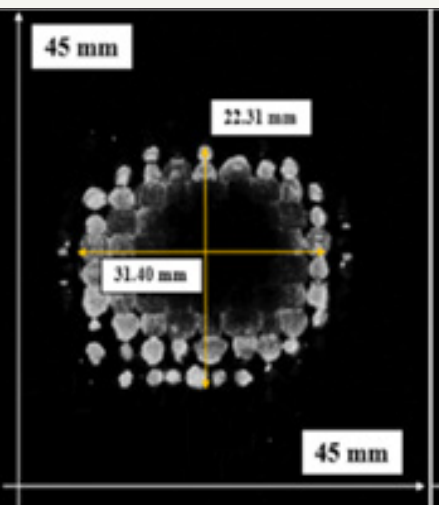

(b)

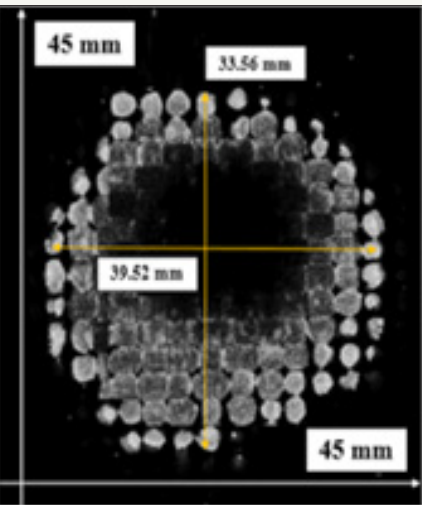

(c)

Figure 10: SAM scanning for overall internal damage (a) Neat CFRP, (b) 2.0 wt.\% MWCNT doping (c) 5.0 wt.\% MWCNT doping.

\section{Conclusion}

This experimental study analyzed the low-velocity impact response of symmetric CFRP laminate at different weight percentage of MWCNTs. Experiments were conducted at impact energy of 94.14J, which is sufficient for fiber breakage in all type of laminates. The significant outcomes of the present investigation are as follow:

A. Impact energy absorbed by laminate with neat ( $0 \mathrm{wt} \%$ MWCNTs) epoxy was 65.16J, which increases by $23.94 \%$ on addition of $2 \mathrm{wt} \%$ MWCNTs in epoxy. On the contrary, absorbed energy decreases by $14.36 \%$ on addition of $5 \mathrm{wt} \%$ MWCNTs in epoxy. Hence, it can be concluded that to maximize impact energy absorption optimization of weight percentage of MWCNTs is required.

B. The Load carrying capacity of the laminate with epoxy having $0 \mathrm{wt} \%, 2 \mathrm{wt} \%$ and $5 \mathrm{wt} \%$ MWCNTs was $16.15 \mathrm{KN}$, 18.44KN and 19.33 KN respectively. Effect of epoxy up gradation (reinforcement of MWCNTs) on the load carrying capacity was insignificant, which is accredited to the fact that fibers govern the load carrying capacity of composites.

The size of pyramidal damage for a laminate having epoxies doped with $2 \mathrm{wt} \%$ MWCNTs is small in comparison with pyramidal damage of laminate having epoxy mixed with $0 \mathrm{wt} \%$ and $5 \mathrm{wt} \%$ of MWCNTs. This is accredited to the bridging action of multiwalled carbon nanotubes around the cracks in laminates having epoxy mixed with $2 w t \%$ MWCNTs, where as an agglomeration of MWCNTs in a CFRP composite having epoxy mixed with $5 \mathrm{wt} \%$ of the MWCNTs which prevents the bridging action and accelerated the crack propagation by providing voids.

\section{References}

1. Iijima S (1991) Helical microtubules of graphitic carbon. Nature 354(6348): 56-58.

2. Warrier A, Godara A, Rochez O, Mezzo L, Luizi F, et al. (2010) The effect of adding carbon nanotubes to glass/epoxy composites in the fibre sizing and/or the matrix. Composites Part A Applied Science and Manufacturing 41(4): 532-538.

3. Garcia E, Wardle B, Johnhar, A, Yamamoto N (2008) Fabrication and multifunctional properties of a hybrid laminate with aligned carbon nanotubes grown In situ. Composites Science and Technology 68(9): 2034-2041.

4. Baltopoulos A, Karapappas P, Vavouliotis A, Paipetis A (2010) Impact and after-impact properties of carbon fibre reinforced composites enhanced with multi-wall carbon nanotubes. Composites Science and Technology 70(4): 553-563.

5. Agrawal S, Singh KK, Sarkar P (2014) Impact damage on fibre-reinforced polymer matrix composite-A review. Journal of Composite Materials 48(3): 317-332.

6. Phang IY, Shen L, Chow SY, Zhang WD (2004) Morphology and mechanical properties of multiwalled carbon nanotubes reinforced nylon-6 composites. Macromolecules 37(19): 7214-7222.

7. Rawat P, Singh KK (2017) An impact behavior analysis of CNT-based fiber reinforced composites validated by LS-DYNA: A review. Polymer Composites 38(1): 175-184.

8. Saravanan M, Babu S, Sivaprasad K, Jagannatham M (2010) Technoeconomics of carbon nanotubes produced by open air arc discharge method. International Journal of Engineering, Science and Technology 2(5).

9. Gojny FH, Wichmann MHG, Fiedler B, Bauhofer W, Schulte K (2005) Influence of nano-modification on the mechanical and electrical properties of conventional fibre-reinforced composites. Composites Part A: Applied Science and Manufacturing 36(11): 1525-1535.

10. Tehrani M, Boroujeni AY, Hartman TB, Haugh TP, Case SW, et al. (2013) Mechanical characterization and impact damage assessment of a woven carbon fiber reinforced carbon nanotubes-epoxy composite. Composites Science and Technology 75: 42-48.

11. Costa P, Silva J, Ansón CA, Martinez MT, Abad MJ, et al. (2014) Effect of carbon nanotube type and functionalization on the electrical, thermal, mechanical and electromechanical properties of carbon nanotube/ styrene-butadiene-styrene composites for large strain sensor applications. Composites Part B: Engineering 61: 136-146.

12. Sevkat E, Liaw B, Delale F, Raju BB (2009) A combined experimental and numerical approach to study ballistic impact response of S2-glass fiber/ toughened epoxy composite beams. Composites Science and Technology 69(7-8): 965-982. 
13. Ghasemnejad H, Furquan ASM, Mason PJ (2010) Charpy impact damage behaviour of single and multi-delaminated hybrid composite beam structures. Materials and Design 31(8): 3653-3660.

14. Chai GB, Zhu S (2011) A review of low-velocity impact on sandwich structures. Proceedings of the Institution of Mechanical Engineers, Part L: Journal of Materials Design and Applications 225(4): 207-230.

15. Iwahori Y, Ishiwata S, Sumizawa T, Ishikawa T (2005) Mechanical properties improvements in two-phase and three-phase composites using carbon nano-fiber dispersed resin. Composites Part A: Applied Science and Manufacturing 36(10): 1430-1439.

16. Singh KK, Singh NK, Jha R (2016) Analysis of symmetric and asymmetric glass fiber reinforced plastic laminates subjected to low-velocity impact. Journal of Composite Materials 50(14): 1853-1863.

17. Singh KK, Singh RK, Chandel PS, Kumar P (2008) An asymmetric FRP laminate with a circular precrack to determine impact-induced damage. Polymer Composites 29(12): 1378-1383.

18. Reid SR, Zhou G (2000) Impact behaviour of fibre-reinforced composite materials and structures. $\left(1^{\text {st }}\right.$ edn), Woodhead Publishing, UK.

19. Qian D, Dickey EC, Andrews R, Rantell T (2000) Load transfer and deformation mechanisms in carbon nanotube-polystyrene composites. Applied Physics Letters 76(20): 2868-2870.
20. Xu X, Thwe MM, Shearwood C, Liao K (2002) Mechanical properties and interfacial characteristics of carbon-nanotube-reinforced epoxy thin films. Applied Physics Letters 81(15): 2833-2835.

21. EM, Sheyka MP, Taha MR (2012) Low-velocity impact of thin woven carbon fabric composites incorporating multi-walled carbon nanotubes. International Journal of Impact Engineering 47: 39-47.

22. Siegfried M, Tola C, Claes M, Lomov SV, Verpoest I, et al. (2014) Impact and residual after impact properties of carbon fiber/epoxy composites modified with carbon nanotubes. Composite Structures 111: 488-496.

23. Ebbesen TW, Ajayan PM (1992) Large-scale synthesis of carbon nanotubes. Nature 358(6383): 220-222.

24. Singh KK, Chaudhary SK, Venugopal R, Gaurav A (2017) Bulk synthesis of multi-walled carbon nanotubes by AC arc discharge method. Journal of Nanomaterials, Nanoengineering and Nanosystems 231(3): 141-151.

25. Li C, Wang D, Liang T, Wang X, Wu J, et al. (2004) Oxidation of multiwalled carbon nanotubes by air: benefits for electric double layer capacitors. Powder Technology 142(2-3): 175-179.

26. Lu KL, Lago RM, Chen YK, Green MLH, Harris PJF, et al. (1996) Mechanical damage of carbon nanotubes by ultrasound. Carbon 34(6): 814-816.
Creative Commons Attribution 4.0

International License

For possible submissions Click Here

\section{Submit Article}

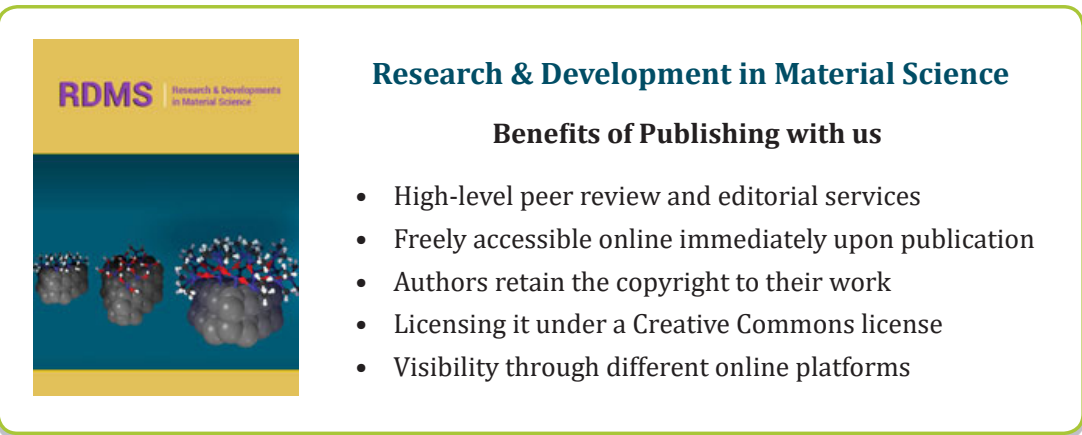

